\title{
Selected flavonoids potentiate the toxicity of cisplatin in human lung adenocarcinoma cells: A role for glutathione depletion
}

\author{
REMY KACHADOURIAN ${ }^{1}$, HEATHER M. LEITNER ${ }^{1}$ and BRIAN J. DAY ${ }^{1,2}$ \\ ${ }^{1}$ Department of Medicine, National Jewish Medical and Research Center; ${ }^{2}$ Departments of Medicine, \\ Immunology and Pharmaceutical Sciences, University of Colorado Health Sciences Center, Denver, CO 80206, USA
}

Received February 12, 2007; Accepted March 29, 2007

\begin{abstract}
Adjuvant therapies that enhance the anti-tumor effects of cis-diammineplatinum(II) dichloride (cisplatin, CDDP) are actively being pursued. Growing evidence supports the involvement of mitochondrial dysfunction in the anti-cancer effect of cisplatin. We examined the potential of using selective flavonoids that are effective in depleting tumor cells of glutathione (GSH) to potentiate cisplatin-mediated cytotoxicity in human lung adenocarcinoma (A549) cells. We found that cisplatin $(40 \mu \mathrm{M}, 48$-h treatment) disrupts the steady-state levels of mitochondrial respiratory complex I, which correlates with elevated mitochondrial reactive oxygen species (ROS) production and cytochrome $c$ release. The flavonoids, 2',5'dihydroxychalcone (2',5'-DHC, $20 \mu \mathrm{M})$ and chrysin $(20 \mu \mathrm{M})$ potentiated the cytotoxicity of cisplatin $(20 \mu \mathrm{M})$, which could be blocked by supplementation of the media with exogenous GSH $(500 \mu \mathrm{M})$. Both 2',5'-DHC and chrysin were more effective than the specific inhibitor of GSH synthesis, L-buthionine sulfoximine (BSO, $20 \mu \mathrm{M}$ ), in inducing GSH depletion and potentiating the cytotoxic effect of cisplatin. These data suggest that the flavonoid-induced potentiation of cisplatin's toxicity is due, in part, to synergetic pro-oxidant effects of cisplatin by inducing mitochondrial dysfunction, and the flavonoids by depleting cellular GSH, an important antioxidant defense.
\end{abstract}

\section{Introduction}

Cisplatin and its analogs are widely used in cancer chemotherapy for the treatment of testicular and lung tumors, despite their ability to injure healthy tissues such as renal tubular and auricular epithelial cells (1). Cisplatin forms DNA adducts, yet its ability to induce programmed cell death (apoptosis) in both cancer and normal cells has been associated with

Correspondence to: Dr B.J. Day, Department of Medicine, National Jewish Medical and Research Center, 1400 Jackson St. Denver, CO 80206, USA

E-mail: dayb@njc.org

Key words: cisplatin, flavonoid, mitochondria, superoxide, cytochrome $c$ the formation of reactive oxygen species (ROS) in the mitochondria, cytochrome $c$ release into the cytosol, and subsequent activation of caspases (2-8). One report suggests that cytochrome $c$ release is required for cisplatin-induced apoptosis, yet a caspase 3 -independent pathway has been reported as well $(8,9)$. The mechanisms by which cisplatin induces the formation of ROS remain unclear. Inhibition of all the mitochondrial respiratory chain complexes has been reported using high concentrations of cisplatin $(100 \mu \mathrm{M})$ in isolated mitochondria (10). Although the formation of mitochondrial DNA (mtDNA) adducts with cisplatin has been demonstrated, the toxicological relevance of such adducts remains poorly investigated (11-13).

Glutathione (GSH) depletion as a potential strategy to sensitize cancer cells has been under investigation for over two decades (14-22). Indeed, GSH and glutathione peroxidase (GPx) play central roles in cellular homeostasis by controlling the levels of ROS, and cancer cells tend to exhibit higher levels of ROS $(22,23)$. Several studies have associated GSH depletion with mitochondrial dysfunction, but the precise mechanism remains unclear (24). GSH depletion is commonly achieved using the inhibitor of GSH synthesis, L-buthionine sulfoximine (BSO), which has been shown to sensitize cancer cells to cisplatin treatment $(19,20)$. However, limitations of this strategy include an inherent lack of specificity towards cancer cells and subsequent side effects (21). A potentially more tumor specific approach to deplete GSH is by using substrates of multidrug resistance proteins (MRPs), a family of ATP-binding cassette $(\mathrm{ABC})$ proteins that are known GSH co-transporters and tend to be over-expressed in cancer cells $(14-17,25)$.

Flavonoids and their precursors hydroxychalcones (HCs) are natural plant products found in high abundance in fruits and vegetables. Although flavonoids are generally viewed as antioxidants, they can also generate ROS depending on their structure and molecular environment (26). In the cell, flavonoids can produce modulatory effects through alterations of protein and lipid kinase signaling pathways (27). Moreover, a number of flavonoids may exert direct and indirect prooxidant effects by inhibiting the mitochondrial respiratory chain complexes I and II and by inducing GSH depletion through MRP1 activation (14,28-31). Most MRP1 'inhibitors' are MRP1 substrates that are competitive inhibitors of drug efflux and are co-transported with GSH, yet verapamil and some flavonoids can induce GSH depletion without being expelled from the cell (31). We recently reported that, among a series of MRP substrates, 


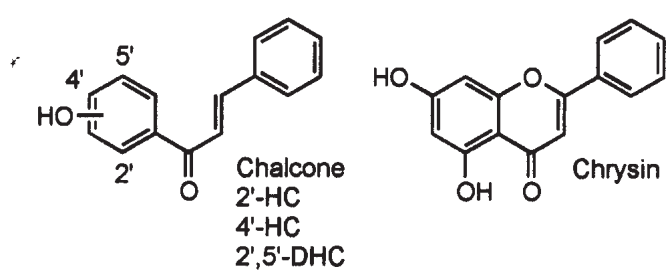

Figure 1. Molecular structures of chalcone (no hydroxyl group), 2'-hydroxychalcone (2'-HC), 4'-hydroxychalcone (4'-HC), 2',5'-dihydroxychalcone $\left(2^{\prime}, 5^{\prime}-\mathrm{DHC}\right)$ and chrysin.

2',5'-dihydroxychalcone (2',5'-DHC) and chrysin (Fig. 1) were the most efficient inducers of GSH depletion in several cancer cell lines (14). It is also worth noting that 2',5'-DHC, in particular, exerts interesting antiangiogenic properties (32).

In this study, we report that: i) cisplatin treatment in A549 cells disrupted the steady-state level of mitochondrial respiratory complex I, which in turn may account for some of the mitochondrial ROS formation; ii) cisplatin's cytotoxicity was potentiated in A549 cells by non-toxic concentrations of 2',5'-DHC and chrysin, and that these effects were attenuated by exogenously added GSH; and iii) the potentiation effect involved increased dysfunction of the mitochondria, as shown by the assessment of cytochrome $c$ release.

\section{Materials and methods}

Chemicals and reagents. Chalcone, 2'-hydroxychalcone (2'-HC), 4'-hydroxychalcone (4'-HC), and 2',5'-dihydroxychalcone (2',5'-DHC) were purchased from Indofine Chemicals Company, Inc. (Hillsborough, NJ). Chrysin, cis-diammineplatinum (II) dichloride (CDDP or cisplatin), L-gluthatione (reduced), pyruvate (sodium salt), phosphoric acid, metaphosphoric acid, sodium phosphate (monobasic), Triton X-100, EDTA, NADH, $\mathrm{K}_{2} \mathrm{HPO}_{4}, \mathrm{KH}_{2} \mathrm{PO}_{4}$, HEPES, DMSO and DMF were from Sigma-Aldrich (St. Louis, MO). Tris-HCl, perchloric acid and methanol were from Fisher (Pittsburgh, PA). MitoSOX and JC-1 were from Molecular Probes (Eugene, OR). Phosphatebuffered saline (PBS) was from Cellgro (Herndon, VA). Protease inhibitor cocktail tablets supplemented with EDTA were from Roche Diagnostics (Indianapolis, IN).

Cell line and culture conditions. Human lung adenocarcinoma (A549) cells were purchased from ATCC (Manassas, VA). They were grown in Ham's F12 medium with 2 mM L-glutamine (ATCC) supplemented with $10 \%$ fetal bovine serum (FBS) and $1 \%$ pen/strep (10,000 unit, Cellgro) at $37^{\circ} \mathrm{C}$ and $5 \% \mathrm{CO}_{2}$ air atmosphere. T-75 or T-150 flasks were used for mitochondrial purification, and 24-well plates for flow cytometry studies, cytosolic GSH measurements, and percentage of LDH release assessment. 2',5'-DHC and chrysin were added from $10 \mathrm{mM}$ stock solutions in DMF, and cisplatin from $10 \mathrm{mM}$ stock solutions in $\mathrm{H}_{2} \mathrm{O} / \mathrm{DMF}$ (1:1).

Mitochondrial isolation. Isolation of A549 mitochondria was achieved through differential centrifugation as previously described (14). Following cisplatin and 2',5'-DHC treatments,
A549 cells were trypsinized (0.04\% trypsin in Puck's EDTA), pelleted by centrifugation $\left(2,000 \mathrm{x}\right.$ g for $10 \mathrm{~min}$ at $\left.4^{\circ} \mathrm{C}\right)$, resuspended in $\mathrm{PBS}$, and spun $\left(2,000 \mathrm{x} \mathrm{g}\right.$ for $10 \mathrm{~min}$ at $\left.4^{\circ} \mathrm{C}\right)$ to yield a final cell pellet. The pellet was resuspended in $550 \mu \mathrm{l}$ of ice-cold hypotonic buffer (10 $\mathrm{mM} \mathrm{NaCl}, 1.5 \mathrm{mM} \mathrm{MgCl}_{2}$, $10 \mathrm{mM}$ Tris- $\mathrm{HCl}, \mathrm{pH} 7.5)$. After $10 \mathrm{~min}$, the cell suspension was homogenized (Kontes glass homogenizer, FisherScientific, Fair Lawn, NJ). Immediately after homogenization, $400 \mu 1$ of $2.5-\mathrm{X}$ mannitol-sucrose buffer was added (525 mM mannitol, $175 \mathrm{mM}$ sucrose, $12.5 \mathrm{mM}$ Tris- $\mathrm{HCl}, 2.5 \mathrm{mM}$ EDTA, $\mathrm{pH}$ 7.5). Addition of $2 \mathrm{ml}$ of ice-cold single-strength mannitolsucrose buffer $(210 \mathrm{mM}$ mannitol, $70 \mathrm{mM}$ sucrose, $5 \mathrm{mM}$ Tris-HCl, 1 mM EDTA, pH 7.5) was added and contents divided into two $1.5 \mathrm{ml}$ centrifuge tubes. Cellular debris was pelleted by centrifugation at $1,300 \mathrm{x} \mathrm{g}$ for $10 \mathrm{~min}$ at $4^{\circ} \mathrm{C}$. Centrifugation was repeated twice and mitochondria from the supernatant were isolated by centrifugation at $17,000 \mathrm{x} g$ for $15 \mathrm{~min}$ at $4^{\circ} \mathrm{C}$. The mitochondrial pellet was washed and centrifuged at $17,000 \times \mathrm{g}$ for $15 \mathrm{~min}$ at $4^{\circ} \mathrm{C}$ to limit cytosolic contamination. Mitochondrial enrichment was determined by the relative activity of a cytosolic enzyme marker (LDH) and a mitochondrial enzyme marker (glutamate dehydrogenase, $\mathrm{GDH})$ in the fractions as previously described (14).

Immunoblotting of mitochondrial respiratory complexes I and II. A549 mitochondria pellets were lysed in a ground glass homogenizer with $50 \mu 1$ of $50 \mathrm{mM}$ HEPES, $0.5 \%$ Triton X-100, pH 7.0 lysis solution. After homogenization, total volume was brought to $10 \mu 1 \mathrm{H}_{2} \mathrm{O}$. Total protein concentration was measured at $595 \mathrm{~nm}$ on Spectra Max 340PC micro-plate reader (Molecular Devices Corp., Sunnyvale, CA) using Coomassie Plus (Pierce, Rockford, IL). PAGEr ${ }^{\circledR}$ Gold Precast Polyacrylamide 4-20\% Tris-Glycine (Cambrex Bio Science, Rockland, ME) were loaded with $10 \mu \mathrm{g}$ protein per well. Samples were run at $125 \mathrm{~V}$ for $75 \mathrm{~min}$ and transferred to PVDF-plus membrane (Osmonics Inc., Westborough, MA) at $100 \mathrm{~V}$ for $1 \mathrm{~h}$. Blocking, washing, and stripping solutions were prepared as suggested by the manufacturer for optimal results with the ECL Plus Western Blot Detection Reagents Kit (Amersham Biosciences, Buckinghamshire, UK). All wash steps were performed in triplicate for $10 \mathrm{~min}$ in Tris-buffered-saline-Tween (TBS-T). Membranes were blocked for $1 \mathrm{~h}$ at room temperature in TBS-T and 10\% horse serum. Complex I $(0.25 \mu \mathrm{g} / \mathrm{ml})$ primary antibody (monoclonal 15 kDa antibody \#A-21342; Molecular Probes, Eugene, OR) was applied for $2.5 \mathrm{~h}$. Secondary antibody (peroxidase-conjugated AffiniPure goat anti-mouse IgG, Jackson ImmunoResearch Laboratories, Inc., West Grove, PA) diluted 1:40,000 in TBS-T, was applied for $30 \mathrm{~min}$. ECL Plus Western Blot Detection Reagents were used to detect proteins. Following complex I detection membranes were submerged in stripping buffer $(100 \mathrm{mM}$ 2-mercaptoethanol, $2 \%$ SDS, $62.5 \mathrm{mM}$ Tris- $\mathrm{HCl} \mathrm{pH}$ 6.7) and incubated at $55^{\circ} \mathrm{C}$ for $45 \mathrm{~min}$ with occasional agitation. Membranes were re-probed for complex II (Molecular Probes monoclonal $70 \mathrm{kDa}$ antibody, \#A-11142) using $0.125 \mu \mathrm{g} / \mathrm{ml}$ antibody. Identical secondary antibody was diluted 1:40,000 in TBS-T.

Flow cytometry. MitoSOX is an analog of hydroethidine and has been used to detect mitochondrial superoxide by flow 
cytometry (33). The results obtained with this method remain qualitative rather than quantitative (34), yet flow cytometry allows the study of specific groups of cells. The oxidation products of MitoSOX were detected using the red channel (FL2). The ratio of red/green fluorescences (FL2/FL1 channels) emitted by JC-1 following cell treatment has been widely used as a marker of mitochondrial depolarization and is based on the differential accumulation of this positively charged molecule into the mitochondria (33). Briefly, drug-treated A549 cells $\left(\sim 2 \times 10^{5}\right)$ were exposed to $5 \mu \mathrm{M}$ MitoSOX or $20 \mu \mathrm{M} \mathrm{JC}-1$ (from 5 and $20 \mathrm{mM}$ stock solutions in DMSO, respectively) for $20 \mathrm{~min}$. The supernatant was removed and the cells scraped in $0.5 \mathrm{ml}$ ice-cold PBS, centrifuged at $2,000 \mathrm{x} \mathrm{g}$ for $15 \mathrm{~min}$, and re-suspended in $0.5 \mathrm{ml}$ ice-cold PBS. Cells were analyzed within 30 min using FACSCalibur flow cytometer (Becton-Dickinson Biosciences, San Jose, CA). The total number of cell counts was 10,000 . The FL2/FL1 ratio was measured using the mean $\mathrm{JC}-1$ fluorescence in each channel.

Cytosolic levels of GSH. Intracellular GSH levels were determined by HPLC-EC (35). Cultured cells from 24-well plates were washed once with $1 \mathrm{ml}$ of PBS and then resuspended in $0.5 \mathrm{ml}$ of distilled water with $40 \mu \mathrm{M}$ digitonin (from a $2 \mathrm{mM}$ stock solution in DMSO) for $30 \mathrm{~min}$ at room temperature. Next, $50 \mu 1$ of $10 \%$ meta-phosphoric acid was added ( $1 \%$ final concentration), the samples were sonicated for $2 \mathrm{~min}$ and centrifuged at $20,000 \mathrm{x}$ g for $10 \mathrm{~min}$, and $0.2 \mathrm{ml}$ of supernatant placed in vials for HPLC analysis. The HPLC column used was Synergi 4u Hydro-RP 80A (150x4.6 mm) from Phenomenex (Torrance, CA) and the mobile phase was sodium phosphate buffer (125 mM sodium phosphate monobasic, $\mathrm{pH}$ adjusted to 3 with phosphoric acid) and $0.9 \%$ methanol. The flow rate was $0.5 \mathrm{ml} . \mathrm{min}^{-1}$. The retention time for GSH in these conditions was 7.5 min. The HPLC instrument was from ESA, Inc. (Chelmsford, MA), equipped with an autosampler (model 540) and a Coul array detector (model $5600 \mathrm{~A}$ ). The potential applied was $+0.75 \mathrm{~V}$ vs. H/Pd electrode, and the injection volume was $5 \mu 1$.

Assessment of cytotoxicity. The MTT assay is commonly used to measure cancer cell survival, yet it has revealed artifacts when measuring the cytotoxicity of prooxidant agents (36). Another simple method to evaluate drug-induced cytotoxicity is using membrane integrity as an index, which is assessed by monitoring the release of cytosolic lactate dehydrogenase (LDH). LDH activity was measured in the culture medium and cell lysates (50 mM HEPES, Triton X-100 0.5\%, $\mathrm{pH}$ 7.0) using a plate reader format as previously described (37). Briefly, $5 \mu 1$ of cell culture supernatant and lysates were incubated with $0.24 \mathrm{mM} N A D H$ in a Tris/ $\mathrm{NaCl} \mathrm{pH} 7.2$ buffer in 96 -well plates for $5 \mathrm{~min}$ at $25^{\circ} \mathrm{C}$. The reaction was started by the addition of $9.8 \mathrm{mM}$ pyruvate and the consumption of NADH followed at $340 \mathrm{~nm}$ for $5 \mathrm{~min}$ at $30^{\circ} \mathrm{C}$. Percent LDH release was calculated as follows: (supernatant LDH/ supernatant LDH + lysate LDH) x 100 .

Immunoblotting of cytochrome $c$. The cytosolic fractions resulting from the mitochondrial purification were concentrated using Centricon YM-10 filters (Millipore, Bedford, MA). A
A

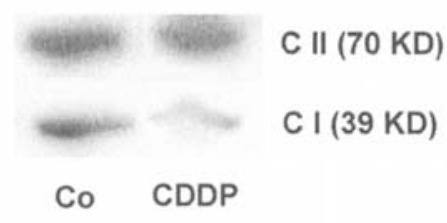

B

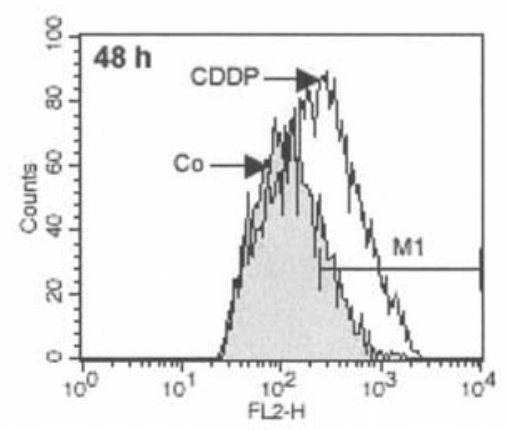

C

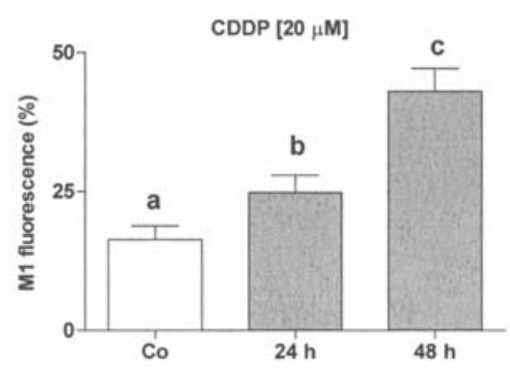

Figure 2. Cisplatin (CDDP) disrupted the steady-state level mitochondrial respiratory complex I and increased mitochondrial superoxide $\left(\mathrm{O}_{2}{ }^{-}\right)$formation in A549 cells. (A) Lower levels of the mitochondrial respiratory complex I were detected when compared to complex II as shown by immunoblotting in CDDP-treated A549 cells ( $40 \mu \mathrm{M}, 48$-h treatment) versus control (Co). Each figure was representative of three samples and the experiment repeated twice. (B) $\mathrm{CDDP}\left(20 \mu \mathrm{M}, 48\right.$-h treatment) induced an increase of $\mathrm{O}_{2} \cdot$ formation in the mitochondria as detected by flow cytometry using the mitochondrial $\mathrm{O}_{2}{ }^{-}$ sensitive dye MitoSOX. (C) Flow cytometry analysis of CDDP-mediated mitochondrial $\mathrm{O}_{2}{ }^{-}$over time at 24 and $48 \mathrm{~h}$. Bars with different letters are statistically different from one another $(n=3, P<0.05)$.

precast gradient 4-20\% SDS PAGE (Bio-Rad Laboratories, Hercules, CA) was loaded with $30 \mu \mathrm{g}$ protein per well. The samples were run and transferred, and the membranes blocked using the same conditions as described above for immunoblotting of complexes I and II. Monoclonal anti-cytochrome $c$ primary antibody $\left(1 \mu \mathrm{g} / \mathrm{ml}\right.$, mouse $\mathrm{IgG}_{2 \mathrm{~b}}$ isotype, BD Biosciences, San Jose, CA) was applied for $2.5 \mathrm{~h}$ with gentle rocking. Secondary antibody (peroxidase-conjugated AffiniPure goat anti-mouse IgG, Jackson ImmunoResearch Laboratories, Inc.) was diluted 1:40,000 in TBS-T and applied for $30 \mathrm{~min}$ with gentle rocking. Cytochrome $c$ was detected using ECL Plus Western Blot Detection Reagents (Amersham Biosciences). Following cytochrome $c$ detection, membranes were submerged in stripping buffer (100 mM 2-mercaptoethanol, 2\% SDS, $62.25 \mathrm{mM}$ Tris- $\mathrm{HCl}, \mathrm{pH}$ 6.7) and incubated at $55^{\circ} \mathrm{C}$ for $45 \mathrm{~min}$ with occasional agitation. Membranes were re-probed for glyceraldehyde 3 phosphate dehydrogenase (GAPDH) as loading standard using monoclonal anti-GAPDH antibody $\left(0.2 \mu \mathrm{g} / \mathrm{ml}\right.$, mouse $\mathrm{IgG}_{2 \mathrm{~b}}$ isotype, Abcam, Cambridge, 
A

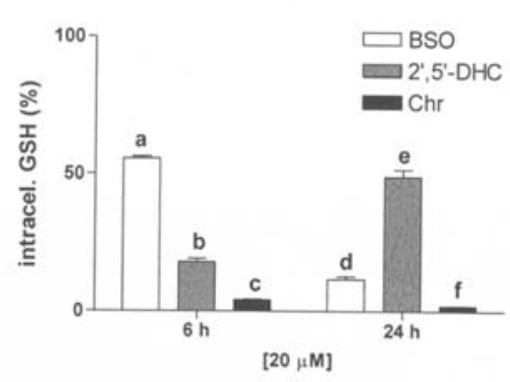

B

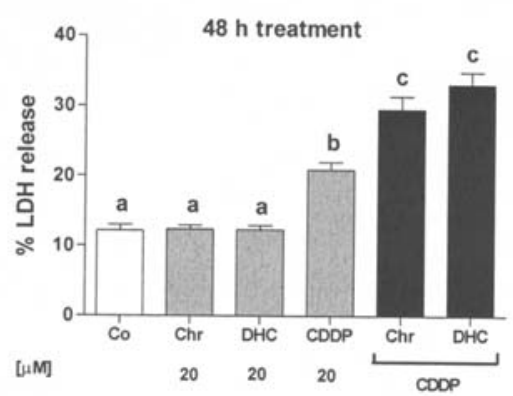

C

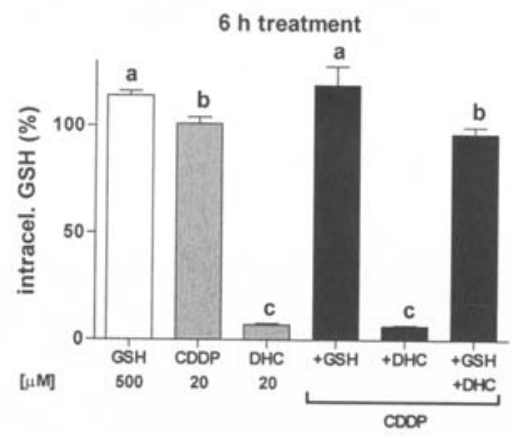

D

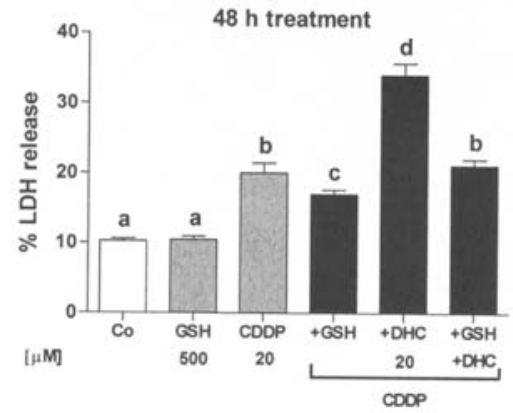

Figure 3. 2',5'-DHC and chrysin induced GSH depletion and potentiated cisplatin-mediated cytotoxicity in A549 cells. (A) At 6-h treatment, the abilities of 2',5'-DHC (DHC, $20 \mu \mathrm{M})$ and chrysin $(\mathrm{Chr}, 20 \mu \mathrm{M})$ to deplete GSH were more important compared to the inhibitor of $\gamma$-glutamylcysteine synthetase BSO $(20 \mu \mathrm{M})(\mathrm{n}=3)$. In the case of 2,5-DHC, however, a rebound of GSH levels was observed at $24 \mathrm{~h}$. (B) 2,5 -DHC and chrysin potentiated the toxicity of cisplatin (CDDP, $20 \mu \mathrm{M}$ ) in A549 cells. (C) Exogenous GSH (500 $\mu \mathrm{M})$ restored cytosolic GSH levels (n=3). (D) Exogenous GSH (500 $\mu$ M) partially protected the cells towards the toxicity of cisplatin and blocked the 2',5'-DHC-mediated potentiation of cisplatin's toxicity. Similar results were obtained with chrysin (data not shown). Bars with different letters are statistically different from one another $(\mathrm{n}=4, \mathrm{P}<0.05)$.

MA). Identical secondary antibody was diluted 1:40,000 in TBS-T and applied for 30 min with gentle rocking.

Statistical analysis. Data are presented as means \pm standard error. Each experimental group consisted of an $n \geq 3$ and the results duplicated at least once. Data were subsequently analyzed for significant differences using ANOVA analysis coupled with a Tukey's range test where significance was preset at $\mathrm{P}<0.05$ (Prizm v.4, GraphPad, San Diego, CA).

\section{Results}

Cisplatin disrupts the steady-state level of mitochondrial respiratory complex I. Although the formation of cisplatinmtDNA adducts has repeatedly been demonstrated, little has been done to evaluate the toxicological relevance of such adducts (11-13). A number of apoproteins of mitochondrial electron transport complexes I, III, IV and V are encoded by mtDNA, whereas complex II is totally encoded by nuclear DNA. Immunoblots from isolated mitochondria demonstrated lower levels of the heavily mitochondria encoded respiratory complex I in cisplatin-treated A549 cells ( $40 \mu \mathrm{M}, 48 \mathrm{~h}$ ) when compared to the nuclear encoded complex II (Fig. 2A). This effect was cisplatin dose-dependent (data not shown). Increased mitochondrial $\mathrm{O}_{2}{ }^{-}$formation has been associated with the release of cytochrome $c$ and apoptosis $(2,8)$, yet cisplatin $(20 \mu \mathrm{M}, 24-$ and 48 -h treatment $)$ induced an increase of mitochondrial $\mathrm{O}_{2} \cdot-$ in A549 cells as shown using flow cyto- metry and the dye MitoSOX (Fig. 2B and C). These results add to the growing data implicating mitochondrial dysfunction in cisplatin's anti-tumor effects.

2',5'-DHC and chrysin potentiate the toxicity of cisplatin in A549 cells. 2',5'-DHC $(20 \mu \mathrm{M})$ and chrysin $(20 \mu \mathrm{M})$ induced GSH depletion in A549 cells (Fig. 3A). After 6-h treatment, this effect was greater when compared to the GSH synthesis inhibitor BSO $(20 \mu \mathrm{M})$. In the case of 2',5'-DHC, however, a rebound of GSH levels was observed after $24 \mathrm{~h}$, possibly due to stimulation of GSH synthesis, as reported previously with some flavonoids (39). Using the same concentrations $(20 \mu \mathrm{M})$, 2',5'-DHC and chrysin were not cytotoxic, yet they potentiated the toxicity of cisplatin in A549 cells (Fig. 3B). Adding exogenous GSH to the media $(500 \mu \mathrm{M})$ restored intracellular GSH levels and significantly protected both the toxicity of cisplatin and the potentiation effect of 2',5'-DHC (Fig. 3C and D). Similar results were obtained using chrysin (not shown). BSO (20 and $50 \mu \mathrm{M}$ ) significantly potentiated the cytotoxicity of cisplatin at 72-h treatment, but not at 48-h treatment (data not shown). Whereas chrysin was more efficient in depleting GSH than 2',5'-DHC in this cell line, the latter was slightly more efficient in potentiating the effect of cisplatin, showing that GSH depletion is only one of the factors involved. 2',5'$\mathrm{DHC}$ is also known to interfere with the mitotic phase of the cell cycle and possibly with the mitochondrial respiratory chain $(29,30)$. When 2',5'-DHC was compared to its analogs chalcone, 4'-hydroxychalcone (4'-HC) and 2'-hydroxychalcone 
Table I. Structure/activity relationship of several hydroxyl derivatives of chalcone in A549 cells.

\begin{tabular}{|c|c|c|c|c|}
\hline & Chalcone & 4'-HC & $2^{\prime}-\mathrm{HC}$ & $2^{\prime}, 5^{\prime}-\mathrm{DHC}$ \\
\hline GSH levels $(\% \mathrm{Co})^{\mathrm{a}}$ & 100 & 56 & 35 & 18 \\
\hline Toxicity $(\% \mathrm{Co})^{\mathrm{b}}$ & None & 72 & 126 & 140 \\
\hline Potentiation effect $(\% \text { CDDP })^{c}$ & None & None & 29 & 46 \\
\hline
\end{tabular}

${ }^{a}$ Intracellular GSH levels (\% compared to control, Co) as measured by HPLC-EC and using $20 \mu \mathrm{M}$ of compound (6-h treatment). ${ }^{\mathrm{b}}$ Toxicity (\% compared to control, Co) as measured by percentage of LDH release and using $40 \mu \mathrm{M}$ of compound (48-h treatment). ${ }^{\mathrm{c} P o t e n t i a t i o n}$ effect of the toxicity of cisplatin (\% compared to $20 \mu \mathrm{M}$ of CDDP) as measured by percentage of LDH release and using $20 \mu \mathrm{M}$ of compound (48-h treatment). Margin of errors were less than $\pm 5 \%$, except for $2^{\prime}, 5^{\prime}$-DHC induced toxicity $( \pm 7 \%)$.

A

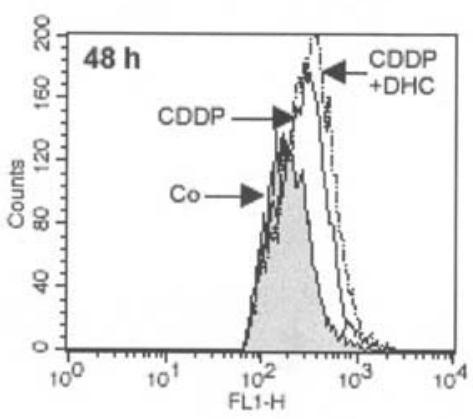

B

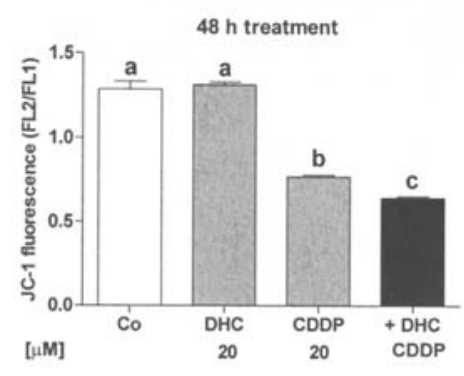

C

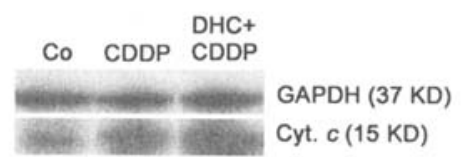

Figure 4. 2',5'-DHC increased the cisplatin-mediated depolarization of the mitochondrial membrane and cytochrome c release. (A and B) As shown using flow cytometry and JC-1 as dye, cisplatin treatment (CDDP, $20 \mu \mathrm{M}$, $48 \mathrm{~h}$ ) induced a depolarization of the mitochondrial membrane, effect that was amplified by adding 2',5'-DHC (DHC, $20 \mu \mathrm{M})$. The FL2/FL1 ratio was measured using the mean fluorescence in each channel. Bars with different letters are statistically different from one another $(n=3, P<0.05)$. (C) As shown by immunoblotting using GAPDH as internal standard, cisplatin treatment (CDDP, $20 \mu \mathrm{M}, 48 \mathrm{~h}$ ) induced the release of cytochrome $c$ (Cyt. $c$ ), which was increased by adding 2',5'-DHC (DHC, $20 \mu \mathrm{M})$. 2',5'-DHC alone had no significant effect (not shown). Each figure was representative of three samples and the experiment was repeated at least twice.

(2'-HC), 2',5'-DHC was the most efficient in depleting GSH in A549 cells, in killing A549 cells, and in potentiating the effect of cisplatin (Table I). These results show an apparent correlation between the ability of hydroxychalcones to induce
GSH depletion with their ability to potentiate the toxicity of cisplatin.

2',5'-DHC and chrysin exacerbate cisplatin-induced mitochondrial dysfunction. The depolarization of the mitochondrial membrane and the subsequent release of cytochrome $c$ are usually seen as the 'point of no return' in mitochondrialmediated apoptosis. Cisplatin treatment $(20 \mu \mathrm{M}, 48 \mathrm{~h})$ in A549 cells induced a depolarization of the mitochondria as shown using flow cytometry and the dye JC-1 (Fig. 4A and B). Whereas 2',5'-DHC alone did not show a decrease in FL2/FL1 ratio, the mitochondrial membrane was further depolarized by adding 2',5'-DHC $(20 \mu \mathrm{M})$ to cisplatin. Also, cisplatin treatment $(20 \mu \mathrm{M}, 48 \mathrm{~h})$ induced a release of cytochrome $c$, which was increased by adding $2^{\prime}, 5^{\prime}$-DHC $(20 \mu \mathrm{M})$ as shown by immunoblotting (Fig. 4C). A shorter cisplatin treatment time $(24 \mathrm{~h})$ induced a slight depolarization of the mitochondrial membrane, but no significant difference between cisplatin alone and cisplatin-2',5'-DHC-treated cells was detected (data not shown). Chrysin (20 $\mu \mathrm{M}, 48$-h treatment) induced an increase in cytochrome $c$ release as well, but we were unable to detect a significant effect on the depolarization of the mitochondrial membrane using JC-1 (data not shown). This result may be due to the limits in the method sensitivity.

\section{Discussion}

ROS have been associated with carcinogenesis but also, paradoxically, with mitochondrial-mediated cell death in cancer cells. In fact, a number of anti-cancer drugs, including adriamycin and cisplatin, induce the formation of mitochondrial ROS, the depolarization of the mitochondrial membrane, and the release of cytochrome $c$ (40). These attributes may play an important role for the side effects of such drugs (neuro, renal and cardiotoxicities) but also for their cytotoxic action in cancer cells. The chemopreventive properties of naturally occurring compounds may also be mediated by ROS, as in the case of 2-methoxyestradiol, an inhibitor of mitochondrial respiratory complex I $(41,42)$. Formation of mitochondrial ROS appears to be increased by reversible glutathionylation of complex I as well (43). GSH depletion sensitizes cisplatin-resistant cancer cells $(19,20)$. Conversely, treatments with $N$-acetyl-L-cysteine, a glutathione ester, or GSH are protective against cisplatininduced toxicity $(44,45)$. Yet, it is important to note the delayed 
nature of cisplatin-induced mitochondrial ROS formation. Whereas inhibitors of the electron transport chain induce an oxidative burst within hours following treatment, the increase of ROS levels induced by cisplatin was significant only after $24 \mathrm{~h}$ of treatment (Fig. 2C). Moreover, cisplatin induced a decrease in the ratio of complexes $\mathrm{I} / \mathrm{II}$, which has previously been associated with the formation of mitochondrial superoxide $\left(\mathrm{O}_{2}^{-*}\right)$ (38). These findings suggest that, at the concentration used in our studies (under $40 \mu \mathrm{M}$ ), cisplatin's target is mtDNA rather than direct inhibition of the electron transport chain (10-13). mtDNA encodes for 13 proteins that are critical for the proper function of the electron transport chain, and the effects of cisplatin and other alkylating agents on mtDNA should not be underestimated. A variety of effects of cisplatin in the cell have been reported, yet the disruption of the assembly of the mitochondrial respiratory chain is, in our view, the most reasonable explanation for cisplatin-induced formation of mitochondrial ROS and subsequent mitochondrial-mediated cell death.

A continuing avenue of research is to combine agents to synergize the anti-tumor effects without increasing damage to normal tissue. Previous studies have shown that lowering tumor cell defenses against chemotherapeutic agents can synergize anti-tumor effects. GSH is an abundant and critical cellular thiol antioxidant. Cellular GSH levels are maintained by synthesis, transport, utilization, and degradation pathways. Early attempts to target these pathways involved the use of inhibitors to block GSH synthesis or glutathione reductase that recycles the oxidized form of glutathione (GSSG) back to the active reduced form (GSH). BCNU (carmustine) is an approved anti-cancer drug that is an alkylating agent and an inhibitor of glutathione reductase (46). BSO is an example of an inhibitor of cellular GSH synthesis that has been used in combination with mephalan or radiotherapy $(21,22)$. A major problem associated with these approaches has been the lack of selectivity. In the past few years, several studies have associated the ability of verapamil to sensitize cancer cells by an MRP-mediated GSH depletion rather than inhibition of drug efflux (15-17). We showed recently that, in three separate cancer cell lines, simple molecules such as 2',5'-DHC and chrysin were more effective than verapamil in depleting cytosolic GSH (14).

We have chosen to target MRP-mediated GSH transport using 2',5'-DHC and chrysin as a new strategy to achieve GSH depletion and to sensitize cancer cells to cisplatin treatment. As shown using A549 cells, when compared to BSO treatment, both 2',5'-DHC and chrysin were more effective in inducing GSH depletion and in potentiating of toxicity of cisplatin. In order to explain this potentiation effect, inhibition of drug efflux cannot be discarded. However, adding GSH to the culture media protected the cells, thus confirming the importance of cytosolic levels of GSH. Also, whereas cisplatin is a substrate of MRP2, chrysin is a substrate of MRP1 rather than MRP2 $(31,47)$, and preliminary results in our laboratory suggest that 2',5'-DHC is not a substrate for MRP2 (data not shown). Although the conjugation of 2',5'-DHC with GSH cannot be ruled out, it cannot account for the dramatic decrease in GSH levels induced by this compound. Overall, our studies suggest that the potentiation effect of cisplatin-induced toxicity results, in part, from synergetic prooxidant effects of

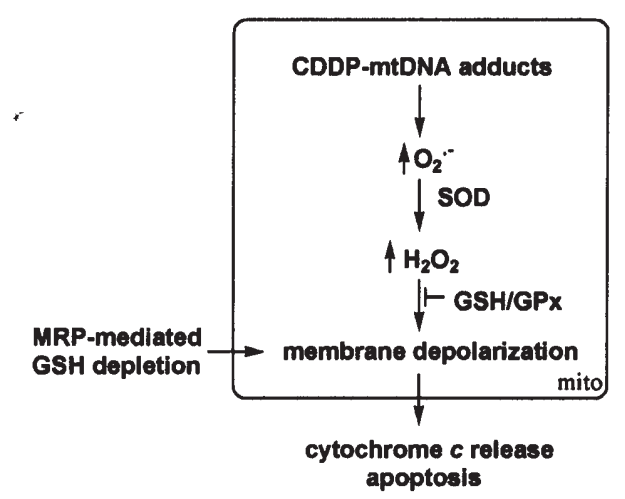

Figure 5. Working hypothesis. The formation of cisplatin-mitochondrial DNA (CDDP-mtDNA) adducts disrupts the assembly of the apoproteins of the mitochondrial respiratory chain, which in turn induces the formation of mitochondrial superoxide $\left(\mathrm{O}_{2}^{-{ }^{-}}\right)$. The latter is converted by superoxide dismutase (SOD) into hydrogen peroxide $\left(\mathrm{H}_{2} \mathrm{O}_{2}\right)$, which mediates the depolarization of the mitochondrial membrane and the release of cytochrome $c$, thus triggering the cascade of events leading to nuclear DNA fragmentation and apoptosis. Flavonoid-induced GSH depletion adds to the mitochondrial membrane depolarization by mechanisms that remain to be clarified.

cisplatin, by inducing a disruption of the assembly of the apoproteins of the mitochondrial respiratory chain, and the selected flavonoids, by depleting the cells of a key antioxidant defense.

Intracellular GSH depletion has been previously associated with mitochondrial dysfunction, including the increased production of ROS by mitochondrial respiratory complex III (24). Since GSH is synthesized in the cytosol and high concentrations are found in the mitochondria (48), cytosolic GSH depletion can indirectly translate into mitochondrial GSH depletion. Mitochondria mainly rely upon GSH and glutathione peroxidase to control hydrogen peroxide $\left(\mathrm{H}_{2} \mathrm{O}_{2}\right)$ levels, and thus lower GSH levels could lead to higher mitochondrial steady-state $\mathrm{H}_{2} \mathrm{O}_{2}$ levels and trigger the formation of mitochondrial pores and the depolarization of the mitochondrial membrane. However, it is worth noting that the depolarization of the mitochondrial membrane is mediated by the oxidation of lipoproteins such as cardiolipin (50), which is located in the inner mitochondrial membrane, and its recycling (reduction) is not necessarily controlled by the pool of mitochondrial GSH. Although it is generally accepted that weakening antioxidant defenses sensitizes cancer cells to prooxidants such as cisplatin, the mechanistic relationship between thiol-redox status and pro- and anti-apoptotic signals is yet to be clarified (Fig. 5). As shown in this study, whereas chrysin was more effective than 2',5'-DHC in depleting cytosolic GSH, 2',5'-DHC was slightly more effective than chrysin in potentiating the toxicity of cisplatin (Fig. 3A and B), suggesting that other mechanisms are involved, possibly direct interference with the mitotic phase of cell cycle and/or with the mitochondrial respiratory chain $(14,30)$. Non-toxic concentrations of 2',5'-DHC and chrysin $(20 \mu \mathrm{M})$ further increased the release of cytochrome $c$ in cisplatin-treated A549 cells (Fig. 4), suggesting that the potentiation effect was also mediated by the mitochondria.

In summary, cisplatin-induced mitochondrial dysfunction is likely due to the disruption of the assembly of the apoproteins 
of the mitochondrial respiratory chain and can be modulated by the ability of selected flavonoids in inducing GSH extrusion from the cell.

\section{Acknowlegments}

This work was supported by NIH grant HL75523 to B.J. Day. The authors wish to thank Jie Huang and William Townend (National Jewish Medical and Research Center) for their help with HPLC and flow cytometry, respectively.

\section{References}

1. Wang D and Lippard SJ: Cellular processing of platinum anticancer drugs. Nat Rev Drug Discov 4: 307-320, 2005.

2. Yen HC, Tang YC, Chen FY, Chen SW and Majima HJ: Enhancement of cisplatin-induced apoptosis and caspase 3 activation by depletion of mitochondrial DNA in a human osteosarcoma cell line. Ann NY Acad Sci 1042: 516-522, 2005.

3. Schweyer S, Soruri A, Heintze A, Radzun HJ and Fayyazi A: The role of reactive oxygen species in cisplatin-induced apoptosis in human malignant testicular germ cell lines. Int $\mathrm{J}$ Oncol 25: 1671-1676, 2004.

4. Huang HL, Fang LW, Lu SP, Chu CK, Luh TY and Lai MZ: DNA-damaging reagents induce apoptosis through reactive oxygen species-dependent Fas aggregation. Oncogene 22: 8168-8177, 2003.

5. Troyano A, Sancho P, Fernandez C, De Blas E, Bernardi P and Aller P: The selection between apoptosis and necrosis is differentially regulated in hydrogen peroxide-treated and glutathione-depleted human promonocytic cells. Cell Death Differ 10: 889-898, 2003.

6. Davis CA, Nick HS and Agarwal A: Manganese superoxide dismutase attenuates cisplatine-induced renal injury: importance of superoxide. J Am Soc Nephrol 12: 2683-2690, 2001.

7. Mueller T, Voigt W, Simon H, Fruehauf A, Bulankin A, Grothey A and Schmoll HJ: Failure of activation of caspase-9 induces a higher threshold for apoptosis and cisplatin resistance in testicular cancer. Cancer Res 63: 513-521, 2003.

8. Kojima H, Endo K, Moriyama H, Tanaka Y, Alnemri ES, Slapak CA, Teicher B, Kufe D and Datta R: Abrogation of mitochondrial cytochrome $\mathrm{c}$ release and caspase-3 activation in acquired multidrug resistance. J Biol Chem 273: 16647-16650, 1998.

9. Henkels KM and Turchi JJ: Cisplatin-induced apoptosis proceeds by caspase-3-dependent and -independent pathways in cisplatinresistant and -sensitive human ovarian cancer cell lines. Cancer Res 59: 3077-3083, 1999.

10. Kruidering M, van de Water B, De Heer E, Mulder GJ and Nagelkerke JF: Cisplatin-induced nephrotoxicity in porcine proximal tubular cells: mitochondrial dysfunction by inhibition of complexes I to IV of the respiratory chain. J Pharmacol Exp Ther 280: 638-649, 1997.

11. Yang Z, Schumaker LM, Egorin MJ, Zuhowski EG, Guo Z and Cullen KJ: Cisplatin preferentially binds mitochondrial DNA and voltage-dependent anion channel protein in the mitochondrial membrane of head and neck squamous cell carcinoma: possible role in apoptosis. Clin Cancer Res 12: 5817-5825, 2006.

12. Talarico T, Cullinane CM, Gray PJ, Webster LK, Deacon GB and Phillips DR: Nuclear and mitochondrial distribution of organoamidoplatinum(II) lesions in cisplatin-sensitive and resistant adenocarcinoma cells. Anticancer Drug Des 16: 135-141, 2001.

13. Giurgiovich AJ, Diwan BA, Olivero OA, Anderson LM, Rice JM and Poirier MC: Elevated mitochondrial cisplatinDNA adduct levels in rat tissues after transplacental cisplatin exposure. Carcinogenesis 18: 93-96, 1997.

14. Kachadourian R and Day BJ: Flavonoid-induced glutathione depletion: potential implications for cancer treatment. Free Radic Biol Med 41: 65-76, 2006.

15. Benlloch M, Ortega A, Ferrer P, Segarra R, Obrador E, Asensi M, Carretero J and Estrela JM: Acceleration of glutathione efflux and inhibition of gamma-glutamyltranspeptidase sensitize metastatic B16 melanoma cells to endothelium-induced cytotoxicity. J Biol Chem 280: 6950-6959, 2005.
16. Trompier D, Chang XB, Barattin R, du Moulinet D' Hardemare A, Di Pietro A and Baubichon-Cortay H: Verapamil and its derivative trigger apoptosis through glutathione extrusion by multidrug resistance protein MRP1. Cancer Res 64: 4950-4956, 2004.

17. Grech KV, Davey RA and Davey MW: The relationship between modulation of MDR and glutathione in MRP-overexpressing human leukemia cells. Biochem Pharmacol 55: 1283-1289, 1998.

18. Meurette O, Lefeuvre-Orfila L, Rebillard A, Lagadic-Gossmann D and Dimanche-Boitrel MT: Role of intracellular glutathione in cell sensitivity to the apoptosis induced by tumor necrosis factor $\alpha$-related apoptosis-inducing ligand/anticancer drug combinations. Clin Cancer Res 11: 3075-3083, 2005.

19. Rudin CM, Yang ZJ, Schumaker LM, Vander Weele DJ, Newkirk K, Egorin MJ, Zuhowski EG and Cullen KJ: Inhibition of glutathione synthesis reverses Bcl-2-mediated cisplatin resistance. Cancer Res 63: 312-318, 2003.

20. Nagata N, Kijima H, Hatanaka H, Asai S, Miyachi H, Takagi A, Miwa T, Mine T, Yamazaki H, Nakamura M, Kondo T, Scanlon KJ and Ueyama Y: Reversal of cisplatin and multi-drug resistance by ribozyme-mediated glutathione suppression. Biochem Biophys Res Commun 286: 406-413, 2001.

21. Bailey HH: L-S,R-buthionine sulfoximine: historical development and clinical issues. Chem Biol Interact 111-112: 239-254, 1998.

22. Batist G, Schecter RL and Alaoui-Jamali MA: The glutathione system and drug resistance. In: Principles of Antineoplastic Drug Development and Pharmacology. Shilsky RL, Milano GA and Ratain MJ (eds). Marcel Dekker Inc., New York, pp503-521, 1996.

23. Nicco C, Laurent A, Chereau C, Weill B and Batteux F: Differential modulation of normal and tumor cell proliferation by reactive oxygen species. Biomed Pharmacother 59: 169-174, 2005.

24. Armstrong JS, Whiteman M, Yang H, Jones DP and Sternberg P: Cysteine starvation activates the redox-dependent mitochondrial permeability transition in retinal pigment epithelial cells. Invest Ophthalmol Vis Sci 45: 4183-4189, 2004.

25. Kruh GD, Gaughan KT, Godwin A and Chan A: Expression pattern of MRP in human tissues and adult solid tumor cell lines. J Natl Cancer Inst 87: 1256-1258, 1995.

26. Cao G, Sofic E and Prior RL: Antioxidant and prooxidant behavior of flavonoids: structure-activity relationships. Free Radic Biol Med 22: 749-760, 1997.

27. Williams RJ, Spencer JP and Rice-Evans C: Flavonoids: antioxidants or signalling molecules? Free Radic Biol Med 36: 838-849, 2004.

28. Hodnick WF, Ahmad S and Pardini RS: Induction of oxidative stress by redox active flavonoids. In: Flavonoids in the Living System. Manthey JA and Buslig BS (ed). Plenum Press, New York, pp131-150, 1998.

29. Go ML, Wu X and Liu XL: Chalcones: an update on cytotoxic and chemoprotective properties. Curr Med Chem 12: 481-499, 2005.

30. Sabzevari O, Galati G, Moridani MY, Siraki A and O'Brien PJ: Molecular cytotoxic mechanisms of anticancer hydroxychalcones. Chem Biol Interact 148: 57-67, 2004.

31. Ballatori N, Hammond CL, Cunningham JB, Krance SM and Marchan R: Molecular mechanisms of reduced glutathione transport: role of the MRP/CFTR/ABCC and OATP/SLC21A families of membrane proteins. Toxicol Appl Pharmacol 204: 238-255, 2005.

32. Nam NH, Kim Y, You YJ, Hong DH, Kim HM and Ahn BZ: Cytotoxic 2',5'-dihydroxychalcones with unexpected antiangiogenic activity. Eur J Med Chem 38: 179-187, 2003.

33. Julian D, April KL, Patel S, Stein JR and Wohlgemuth SE: Mitochondrial depolarization following hydrogen sulfide exposure in erythrocytes from a sulfide-tolerant marine invertebrate. J Exp Biol 208: 4109-4122, 2005.

34. Zhao H, Joseph J, Fales HM, Sokoloski EA, Levine RL, Vasquez-Vivar J and Kalyanaraman B: Detection and characterization of the product of hydroethidine and intracellular superoxide by HPLC and limitations of fluorescence. Proc Natl Acad Sci USA 102: 5727-5732, 2005.

35. Bode AM and Rose RC: Analysis of water-soluble antioxidants by high-performance liquid chromatography with electrochemical detection. In: Oxidants and Antioxidants, part A, Methods in Enzymology. Packer L (ed). Vol. 299. Academic Press, San Diego, pp77-83, 1999.

36. Bernhard D, Schwaiger W, Crazzolara R, Tinhofer I, Kofler R and Csordas A: Enhanced MTT-reducing activity under growth inhibition by resveratrol in CEM-C7H2 lymphocytic leukemia cells. Cancer Lett 195: 193-199, 2003. 
37. Day BJ, Shawen S, Liochev SI and Crapo JD: A metalloporphyrin superoxide dismutase mimetic protects against paraquat-induced endothelial cell injury in vitro. J Pharmacol Exp Ther 275: 1227-1232, 1995.

38. Velsor LW, Kovacevic M, Goldstein M, Leitner HM, Lewis W and Day BJ: Mitochondrial oxidative stress in human hepatoma cells exposed to stavudine. Toxicol Appl Pharmacol 199: 10-19, 2004.

39. Myhrstad MC, Carlsen H, Nordstrom O, Blomhoff R and Moskaug JO: Flavonoids increase the intracellular glutathione level by transactivation of the gamma-glutamylcysteine synthetase catalytical subunit promoter. Free Radic Biol Med 32: 386-393, 2002.

40. Armstrong JS: Mitochondria: a target for cancer therapy. Br J Pharmacol 147: 239-248, 2006.

41. Hail N: Mitochondria: a novel target for the chemoprevention of cancer. Apoptosis 104: 687-705, 2005.

42. Hagen T, D'Amico G, Quintero M, Palacios-Callender M, Hollis V, Lam F and Moncada S: Inhibition of mitochondrial respiration by the anticancer agent 2-methoxyestradiol. Biochem Biophys Res Commun 322: 923-929, 2004.

43. Taylor ER, Hurrell F, Shannon RJ, Lin T-K, Hirst J and Murphy MP Reversible glutathionylation of complex I increases mitochondrial superoxide formation. J Biol Chem 278: 19603-19610, 2003.
44. Roller A and Weller M: Antioxidants specifically inhibit cisplatin cytotoxicity of human malignant glioma cells. Anticancer Res 18: 4493-4498, 1998.

45. Anderson ME, Naganuma A and Meister A: Protection against cisplatin toxicity by administration of glutathione ester. FASEB J 4: 3251-3255, 1990

46. Wasserman TH: The nitrosoureas: an outline of clinical schedules and toxic effects. Cancer Treat Rep 60: 709-711, 1976.

47. Van Zanden JJ, Wortelboer HM, Bijlsma S, Punt A, Usta M, Bladeren PJ, Rietjens IM and Cnubben NH: Quantitative structure activity relationship studies on the flavonoid mediated inhibition of multidrug resistance proteins 1 and 2. Biochem Pharmacol 69: 699-708, 2005.

48. Soderdahl T, Enoksson M, Lundberg M, Holmgren A, Ottersen OP, Orrenius S, Bolcsfoldi G and Cotgreave IA: Visualization of the compartmentalization of glutathione and protein-glutathione mixed disulfides in cultured cells. FASEB J 17: 124-126, 2003.

49. Meister A: Mitochondrial changes associated with glutathione deficiency. Biochim Biophys Acta 1271: 35-42, 1995.

50. Kagan VE, Borisenko GG, Tyurina YY, Tyurin VA, Jiang J, Potapovich AI, Kini V, Amoscato AA and Fujii Y: Oxidative lipidomics of apoptosis: redox catalytic interactions of cytochrome $c$ with cardiolipin and phosphatidylserine. Free Radic Biol Med 37: 1963-1985, 2004. 